\title{
Ensino de História, um campo de pesquisa: reflexões sobre os livros didáticos
}

André Mendes Salles*

Resumo: O Ensino de História hoje se constitui como um frutífero espaço de discussões e investidas acadêmicas. Com as renovaçóes teórico-metodológicas que se intensificaram, sobretudo na década de 1980, o livro didático se tornou objeto e fonte de pesquisa para os historiadores mais sensíveis a tais renovações. Entendemos o ensino de História e as questões a ele relacionadas como fazendo parte constitutiva da própria reflexão do historiador. Assim sendo, este artigo pretende discutir as diretrizes e tendências nas produções sobre os livros didáticos nas últimas décadas. Intenciona-se também discutir algumas das funções do livro didático, pretendendo estabelecer possíveis definições do que seja este objeto cultural.

Palavras-chave: Ensino de História, Livro didático, Historiografia.

Abstract: The teaching of History today consists of a fruitful area of discussion and academic research. With renovations in methodological theory becoming especially intense during the 1980`s, textbooks became historical objects and sources for historical research. The teaching of History and related questions are understood to be a reflection of the historian himself. Because of this, this article aims to discuss the direction and tendencies in research and publications on textbook in the last few decades.

* Graduado em História pela Universidade Federal de Pernambuco. Mestrando em História pela Universidade Federal da Paraíba. Bolsista CAPES. E-mail: andremendes.s@ hotmail.com 
In addition, this article will elaborate the function of textbooks, and define their role as cultural objects.

Keywords: Teaching of History, Textbook, Historiography.

O Ensino de História hoje se constitui como um frutífero espaço de discussões e investidas acadêmicas e dispõe de uma gama de trabalhos dos mais diversificados. A grande maioria desses foi desenvolvida nos Programas de Pós-Graduação em Educação (PPGE); comparativamente, pouco se produziu acerca desse campo de pesquisa nos Programas de Pós-Graduação em História (PPGH). Contudo, esse panorama, felizmente, vem se modificando, pois alguns PPGH's já possuem linhas de pesquisa específicas sobre Ensino de História, a exemplo da Universidade Federal da Paraíba - UFPB, pioneira nesse campo, e da Universidade Estadual de Londrina - UEL. Apesar dessa mudança de mentalidade, quer dizer, apesar de considerar o Ensino de História como um objeto de pesquisa não só da área educacional, mas também como objeto de pesquisa próprio do historiador, esse processo se desenrola ainda de maneira muito tímida. A esse respeito, diz uma importante pesquisadora da área:

Historicamente, as Universidades no Brasil pouco se voltaram para a questão do Ensino. Na pesquisa histórica e sobre o ensino de História, não foi diferente. O ensino de História foi visto, até a década de 1960, como área de formação, não como objeto de pesquisa (OLIVEIRA, 2003, p. 38).

"O Ensino de História é uma face da História como conhecimento, é a História em situação de ensino", diz Marcos Silva (SILVA, 2007, p.275). Assim, o autor reforça nossa perspectiva e nos convida, nós historiadores, a reaver o campo de pesquisa Ensino de História à própria História. Assim:

[...] embora o Ensino de História seja uma face da História como conhecimento, esta última se cindiu e deixou de ver com clareza aquela dimensão como parte de seu ser. Cabe-nos, então, ajudar a História não fugir de si, a se reaver integralmente, a recuperar aquele viés como sua expressão legítima (SILVA, 2007, p. 275). 
Talvez tal estado de coisas possa ser explicado na senil concepção hierárquica entre os cursos de Licenciatura e Bacharelado em História, donde aos bacharéis é delegada toda a responsabilidade na produção do conhecimento científico, restando aos licenciados, a pouco nobre função de reproduzir tais conhecimentos, que foram elaborados por outros e em outros locais desconhecidos dos mesmos.

Desde modo, Ilka Mesquita e Ernesta Zamboni, em instigante artigo, afirmam:

Nesse sentido, voltamos o olhar para o modelo de formação do professor de História que foi estruturado nas décadas de 1960 e 1970 e que permaneceu na década de 1980, na qual predominava a concepção de cursos de licenciatura baseados na transmissão de conhecimentos históricos e em técnicas pedagógicas trabalhadas pelas didáticas e no estágio supervisionado. Nesse modelo, o saber-fazer prático é submetido hierarquicamente ao como fazer da ciência, pois o professor formador ensinava o futuro professor a trabalhar com as ferramentas mais usuais: livro, quadro e giz. Isso significa que o professor formado nesse modelo deveria apenas ater-se a determinadas técnicas que promovessem o repasse mecânico do conhecimento produzido pelos doutos, aqueles investigadores que detêm e produzem o conhecimento científico (MESQUITA; ZAMBONI, 2008, p. 133).

Ainda ao que concerne a tal concepção hierárquica e dicotômica da formação do historiador, que persiste aos dias atuais, Mesquita e Zamboni afirmam que as "mudanças educacionais, consolidadas nos anos 1990 e no início do século XXI, continuam apresentando velhos problemas, como as dicotomias licenciatura/ bacharelado, ensino/pesquisa, teoria/prática” (2008, p. 134).

A própria Associação Nacional de História - ANPUH, antes Associação Nacional de Professores Universitários de História, já traz, no bojo de sua trajetória, a polêmica discussão entre pesquisa/ensino, o que pode ser constatado na modificação do nome da entidade, devido à inserção de professores do Ensino Básico e de alunos de pós-graduação como sócios.

Essa inclusão gerou acirradas contendas, fato que pode ser claramente observado na entrevista da professora Déa Ribeiro 
Fenelon às pesquisadoras Mesquita e Zamboni (2008), ao falar sobre as reações a esse projeto de mudança, o qual tem a própria entrevistada como uma das autoras:

Mas o que era a reação? Era muito pelo lado de que a associação era uma associação científica, de conhecimentos, de produção e apresentação de trabalhos. Era uma coisa dos "historiadores". Fazia-se muito essa diferença. E o professor ainda estava numa fase em que não produzia, que não era um pesquisador. Houve uma reação também grande a proposta. A professora Cecília Westphalen, que é uma das primeiras presidentes da associação, rasgou o estatuto e falou que a gente ia destruir a ANPUH (MESQUITA; ZAMBONI, 2008, p. 139).

O relato da professora Fenelon reforça nossa ideia da forte hierarquização da pesquisa em detrimento do ensino, como se este não passasse de uma simplória reprodução de conhecimentos. É evidente que tal celeuma também possui imbricações políticas, como por exemplo, a luta contra os Estudos Sociais implantado pelo Governo Militar, mas que, no momento, não nos interessa aprofundar.

É lógico também que a reação a tal projeto, por parte de alguns sócios da entidade, tivesse uma preocupação de manutenção de status quo. Assim, como forma de preservação de um espaço de pesquisa que não fosse abalado por professores do Ensino Básico e/ou alunos de pós-graduação, foi criada uma nova instituição, a então Sociedade Brasileira de Pesquisa Histórica.

Devemos destacar que, há muito, 'caiu por terra' a velha ideia de que eram somente os alunos formados no bacharelado quem realizavam cursos de pós-graduação strito senso. Além disso, defendemos, assim como as pesquisadoras Mesquita e Zamboni, que a "docência, o ensino e a reflexão sobre a formação de professores de história fazem parte do ofício do historiador". (2008, p. 159).

Ainda nessa perspectiva, e seguindo a trilha traçada pelas pesquisadoras Costa e Oliveira, percebemos que: 
Essa mudança no enfoque [da área educacional - PPGE - para a histórica-PPGH. Grifo meu] foi proporcionada também pelo aumento significativo do número de trabalhos sobre ensino de História. Trabalhos, antes esporádicos e centrados na pedagogia, tornam-se cada vez mais presentes nas reflexões de licenciados e bacharéis em História pensando a sua própria área e o seu ensino (COSTA; OLIVEIRA, 2007, p. 155).

Com isso, não estamos querendo deslegitimar ou mesmo transferir as pesquisas dos PPGE's para os PPGH's. Ao contrário, reconhecemos a vital importância que os Programas de PósGraduação em Educação exerceram (até mesmo como forma de resistência dos pesquisadores do Ensino de História) e ainda exercem (e tomara que assim continue).

Entendemos o Ensino de História como uma instância da ciência da História. Não se escreve História sem pensar nos usos que dela fazemos, e um desses usos é, justamente, o ensino. (RÜSEN, 2006). Assim, é preciso que os Programas de PósGraduação em História recuperem a área Ensino de História como parte constitutiva da própria disciplina, ou, como diz Marcos Silva (2007), que tomem o Ensino de História como área de conhecimento da própria História.

Nessa perspectiva, entendemos que a História, enquanto disciplina escolar, merece um espaço maior dentre as produções acadêmicas, sobretudo nos Programas de Pós-Graduação em História. Interessa-nos, aqui, discutir alguns dos rumos que as pesquisas sobre os livros didáticos assumiram.

\section{As pesquisas sobre o livro didático}

Ao ser questionado sobre qual o livro didático dentre uma gama de livros diversos, talvez soubéssemos identificar com facilidade, mas, se questionado sobre o que, de fato, faz de um livro, didático, talvez encontrássemos um pouco mais de dificuldade. 


\section{Como, enfim, caracterizar um livro didático e como os pesqui- sadores que se debruçam sobre tal estudo o concebem? ${ }^{1}$ Circe Bittencourt, ao tratar a questão, afirma:}

A familiaridade com o uso do livro didático faz que seja fácil identificá-lo e estabelecer distinções entre ele e os demais livros. Entretanto, trata-se de objeto cultural de difícil definição, por ser obra bastante complexa, que se caracteriza pela interferência de vários sujeitos em sua produção, circulação e consumo. Possui ou pode assumir funções diferentes, dependendo das condiçôes, do lugar e do momento em que é produzido e utilizado nas diferentes situações escolares. É um objeto de "múltiplas facetas", e para sua elaboração e uso existem muitas interferências (BITTENCOURT, 2004, p. 301).

\section{Tentando encontrar uma definição para os livros didáticos, Choppin diz o seguinte:}

Se hoje consideramos o livro didático como um objeto banal, um objeto tão familiar que parece inútil definir, o historiador que se interessa pela evolução dos livros escolares - ou das edições escolares - se depara, logo de início, com um problema de definição. A natureza da literatura escolar é complexa porque ela se situa no cruzamento de três gêneros que participam, cada um em seu próprio meio, do processo educativo: de início, a literatura religiosa de onde se origina a literatura escolar, da qual são exemplos, no Ocidente cristão, os livros escolares laicos "por perguntas e respostas", que retomam o método e a estrutura familiar aos catecismos; em seguida, a literatura didática, técnica ou profissional que se apossou progressivamente da instituição escolar, em épocas variadas entre os anos 1760 e 1830, na Europa -, de acordo com o lugar e o tipo de ensino; enfim, a literatura "de lazer", tanto a de caráter moral quanto a de recreação ou de vulgarização, que inicialmente se manteve separada do universo escolar, mas à qual os livros didáticos mais recentes e em

1 Bittencourt destaca que, em sala de aula, os materiais didáticos utilizados não se restringem aos livros escolares. Ela apresenta dois tipos de materiais didáticos. O primeiro tipo são os suportes informativos, ou seja, aqueles que têm previamente estabelecida uma finalidade didática. Podemos citar como exemplo os próprios manuais didáticos e paradidáticos, assim como apostilas, CD-ROM's, atlas e etc. O segundo tipo são denominados pela autora como documentos, ou seja, aqueles materiais que em sua produção não se teve, como finalidade, uma preocupação didática, mas passam a ser utilizados como tal por professores, que realizam o processo de didatização desses materiais. Como exemplo, citamos filmes, minisséries televisivas, músicas, literatura e etc (BITTENCOURT, 2004, p. 296-297). 
vários países incorporaram seu dinamismo e características essenciais. Essas categorias, sem se excluírem, frequientemente se interpenetram [...] (CHOPPIN, 2004, p. 552).

Essa extensa citação serve para que pensemos acerca da complexidade da constituição dos livros escolares, ainda mais porque tais textos, além de estarem no entrecruzamento dos três gêneros acima citados, também estão no cruzamento da cultura, pedagogia, produção editorial e sociedade. ${ }^{2}$

Ainda na busca de um conceito de livro didático, nos reportamos a Oliveira (2009), que afirma não ser suficiente a definição que os dicionários de Língua Portuguesa oferecem. Assim, mais do que "um conjunto de folhas impressas e reunidas em volume encadernado ou brochado com fins de instruir" (LAROUSSE, 1992, apud Oliveira, 2009, p. 13), o livro didático tem como uma de suas principais características a materialização da disciplina escolar.

Uma segunda característica destacada por Oliveira (2009) é o suporte do livro didático, o papel. Além disso, esse material difere dos textos eletrônicos, pois é escrito de "forma linear e seqüencial. Composto por autores e editores, possui unidade temática, é finito e o relacionamento entre as suas unidades é mediado por sumário e índices (ao contrário dos hiper-textos)" (OLIVEIRA, 2009, p. 14).

O planejamento e a organização em situações didáticas são, segundo Oliveira (2009), a última característica que faz de um livro, didático. Assim, comungamos da mesma opinião do professor Itamar Oliveira, que afirma:

Livro didático é, portanto, um artefato impresso em papel, que veicula imagens e textos em formato linear e sequiencial, planejado, organizado e produzido especificamente para uso em situações didáticas, envolvendo predominantemente alunos e professores, e que tem a função de transmitir saberes circunscritos a uma disciplina escolar. Essa é a imagem que faço quando penso em livro didático (OLIVEIRA, 2009, p. 14).

2 Choppin (2004), baseando-se em Chris Stray, chega a defender tal ideia. 
Destarte, Oliveira ressalta pelo menos seis funções que podem exercer os livros escolares, quais sejam: "reproduzir ideologia; difundir o currículo oficial; condensar princípios e fatos das ciências de referência; guiar o processo de ensino; guiar o processo de aprendizagem; possibilitar formação continuada" (OLIVEIRA, 2009, p. 14).

Tendo em vista essa complexa natureza dos livros escolares e suas múltiplas facetas, recorremos a Chopin (2004), que também realça a multiplicidade de suas funções, destacando quatro essenciais:

Função curricular, cuja análise que se faz do livro didático é aquela que o coloca como "depositário de conteúdos escolares", ou seja, como um "suporte básico e sistematizador privilegiado dos conteúdos elencados pelas propostas curriculares" (BITTENCOURT, 2008, p. 72). Nesse sentido, os manuais didáticos tornam-se "um instrumento fundamental na própria constituição dos saberes escolares" (BITTENCOURT, 2004, p. 302).

Contudo, devemos levar em conta, como nos alerta Décio Gatti Jr. (2004), que as relações entre os órgãos públicos responsáveis pela educação e as editoras didáticas são mais complexas do que imaginamos e representam uma via de influências de mão dupla. Isso quer dizer que não só as políticas públicas educacionais influenciam as editoras no que concerne ao conteúdo dos livros didáticos, mas também estas influenciam as autoridades públicas no momento de se elaborar o currículo (GATTI Jr., 2004, p. 22-23). Nessa perspectiva, "provavelmente nenhum material escolar sofreu tanto as influências das leis de mercado quanto esse. Fundamentalmente porque as políticas do livro escolar mantiveram conectados os interesses estatais aos privados" (CORRÊA, 2000, p. 22).

Função instrumental, que apresenta o livro didático como suporte de métodos e técnicas de aprendizagem. Nessa análise, o livro escolar é avaliado como um instrumento pedagógico, uma vez que produz técnicas de aprendizagem como exercícios, questionários, leituras complementares e sugestões de trabalho em equipe e/ou individual (CHOPPIN, 2004; BITTENCOURT, 2004; 2008a; 2008b). 
Função ideológica ou cultural, que privilegia o livro didático como sendo um veículo portador de sistemas de valores e ideologias, carregadas das concepções, das ideias, dos conceitos e dos preconceitos de uma determinada época: aquela em que foi escrito (CHOPPIN, 2004; BITTENCOURT, 2004, 2008; 2008). Nesse sentido, o livro didático ultrapassa a questão meramente pedagógica, apresentando "implicações políticas, econômicas, ideológicas e teóricas” (CAIMI, 1999, p. 28). Afinal de contas, como nos alerta Caimi (1999, p. 43)

O autor de livros didáticos, assim como o historiador, faz opções entre diferentes temas, periodizações, fontes, métodos, etc., os quais são condicionados pela época em que vivem, pelo seu lugar social, pela sua visão de mundo. Não há, pois, absoluta neutralidade e objetividade; ainda que se esforcem para evitar a parcialidade, não há como se desvencilhar totalmente desses condicionamentos. ${ }^{3}$

Deste modo, entendemos o livro didático como um produto produzido por grupos sociais que, intencionalmente ou não, perpassam sua forma de pensar e agir, portanto, suas identidades culturais e tradiçôes. Nesse sentido, é preciso concebê-lo numa "complexa teia de relações e de representações" (BITTENCOURT, 2008 b, p. 14), donde se misturam interesses públicos e privados. Assim, o "material didático aparentemente simples de se identificar", torna-se de "difícil definição" (ibidem, p. 14).

Choppin ainda destaca uma quarta função: a documental, segundo a qual o livro didático forneceria "um conjunto de documentos, textuais ou icônicos, cuja observação ou confrontação podem vir a desenvolver o espírito crítico do aluno" (CHOPPIN, 2004, p. 553).

O livro didático pode ser caracterizado, ainda, enquanto produto mercadológico, uma vez que está inscrito em uma lógica mercantil de produção e circulação, obedecendo, deste modo, às técnicas de fabricação e comercialização, inerentes ao processo de mercantilização. Tal perspectiva vem ganhando espaço em produções acadêmicas, ainda mais porque o livro escolar representa,

3 Acerca do lugar-social referido por Caimi (1999), ver: Certeau (1982). 
desde algum tempo, um importante ramo para as editoras, e é, hoje, indubitavelmente, a atividade mais rentável do setor editorial brasileiro, cujo maior comprador é o Estado. Deste modo, como produto mercadológico, o livro didático sofre influências do mercado editorial, que como demonstram pesquisas recentes, tem um papel preponderante no resultado final do livro. ${ }^{4}$

Como pudemos perceber, o livro didático possui várias facetas, e deve ser entendido - ou é entendido por nós -, portanto, como um objeto cultural, cujas possibilidades são plurais.

Realizar um estudo sobre o estado da arte da pesquisa sobre o livro didático seria inviável e exaustivo para a pesquisa que nos propomos. Essa, portanto, não é a nossa intenção, interessando-nos tão somente discutir algumas das diretrizes e tendências acerca das produções didáticas das últimas décadas.

Choppin (2004) enfatiza que as pesquisas históricas acerca dos manuais e ediçốes escolares apresentam múltiplas formas possíveis de abordagens. No entanto, destaca duas categorias principais de análise.

A primeira se refere àquelas pesquisas que concebem o livro didático como um documento histórico. São pesquisas que privilegiam as análises dos conteúdos dos textos escolares em detrimento do livro como produto fabricado. Assim:

a história que o pesquisador escreve não é, na verdade, a dos livros didáticos: é a história de um tema, de uma noção, de um personagem, de uma disciplina, ou de como a literatura escolar foi apresentada por meio de uma mídia particular (CHOPPIN, 2004, p. 554).

A segunda categoria de análise refere-se àquelas que negligenciam os conteúdos contidos nesses manuais didáticos, tratando-os como produtos fabricados. Tais apreciações dirigem a atenção diretamente ao livro didático, como suas formas de produção, editoração, distribuição, em detrimento dos seus conteúdos. No Brasil, podemos destacar como principais exemplos as obras de Kazumi Munakata (1997) e Décio Gatti Jr. (2004; 2005).

4 Sobre o livro didático enquanto produto mercadológico, ver: Cassiano $(2003 ; 2004 \mathrm{a}$; 2004b; 2007); Gatti Jr. (2004); Munakata (1997). 
Devemos destacar que as análises que privilegiam a função ideológica do livro didático vêm sendo bastante criticadas. Tal fato talvez se explique devido à realização, nas décadas de 1970 e 1980, de uma verdadeira "caça às bruxas nos livros didáticos, em que se flagrava ideologia em cada frase, palavra ou vírgula" (MUNAKATA, 2004, p. 10).

Muitas dessas obras que seguiram a perspectiva ideológica se assentaram em dois pilares excludentes entre si: as primeiras viam nos livros didáticos o grande vilão do ensino brasileiro, imputando-lhes todas as mazelas. As segundas concebiam os livros escolares como "panacéia universal", na expressão utilizada pela professora Fonseca (2003, p. 52).

Uma e outra, a nosso ver, trazem sérias problemáticas que merecem uma melhor reflexão. A primeira porque defende a extinção ou a não utilização dos livros escolares, e a segunda por acreditar que "seja possível existir 'um livro didático ideal', uma obra capaz de solucionar todos os problemas do ensino, um substituto do trabalho do professor" (BITTENCOURT, 2004, p. 300. Grifo da autora).

Em artigo bastante conhecido, Munakata (2003) aponta que, nas décadas de 1970 e 1980, fez sucesso um gênero literário que poderia ser denominado 'as belas mentiras'. Assim sendo:

Uma série de pesquisas acadêmicas dedicaram-se a flagrar nos livros didáticos e paradidáticos brasileiros a presença insidiosa da mentira, da manipulação, do preconceito, da mistificação, da legitimação da dominação e da exploração burguesas - em suma, da ideologia. Os títulos e os subtítulos de algumas dessas pesquisas já indicavam-lhes a intenção: versão fabricada, história mal contada, belas mentiras (MUNAKATA, 2003, p. 271).

As belas mentiras: a ideologia subjacente aos textos didáticos, livro de Deiró Nosella, foi publicado no final da década de 1970. Analisando as obras didáticas do ano de 1977 da rede de ensino do Espírito Santo, da $1^{\mathrm{a}}$ a $4^{\mathrm{a}}$ série, a autora tinha como objetivo apontar os textos escolares como um instrumento da classe dominante. Tais livros, segundo a autora, escamoteavam os conflitos de classe "com a função de mascarar um mundo real, contraditório 
e injusto, de acordo com os interesses da classe hegemônica" (NOSELLA, 1981, p. 177, apud GALZERANI, p. 107, 1997). Nesse sentido, consideramos os questionamentos de Galzerani, ao realizar um estudo das produções sobre os livros didáticos desse período, fundamentais:

Não conteriam [os livros escolares] também outros elementos rela-cionados a outras visṍes da sociedade, absorvidos e apresentados pelo autor da obra, até mesmo para garantir sua aceitação por uma parcela mais ampla da população? Em outras palavras, até que ponto o conteúdo do livro didático constitui apenas uma máscara que impede o conhecimento da vida social? Ou será que sua linguagem contraditória e ambígua não só esconderia, como também expressaria, os conflitos da própria sociedade? Em nossa opinião, a autora [Nosella] apresenta uma visão unidimensional da ideologia do livro didático (GALZERANI, 1997, p. 107).

Outra obra, destacada por Munakata (1997), e que faz parte do rol 'as belas mentiras', é a Ideologia no livro didático, de Ana Lúcia Faria (1996), para quem o livro se resumiria praticamente em ser um veículo portador de uma ideologia: a ideologia burguesa.

O objetivo principal de Faria foi tentar perceber a categoria conceitual 'trabalho' nos livros didáticos das séries inicias do Ensino Fundamental $\left(2^{\mathrm{a}}, 3^{\mathrm{a}} \mathrm{e} 4^{\mathrm{a}}\right.$ séries $)$. Além da análise dos livros didáticos (num total de 35 didáticos e 6 editoras dos livros mais vendidos de 1977), entrevistou crianças vinculadas às séries dos livros analisados. A tônica das entrevistas foi apreender como essas crianças, que foram, segundo critérios da autora, segregadas em origens burguesa e proletária, concebiam o trabalho.

Faria (1996, p. 70) afirma que "dependendo do referencial teórico que se adote, o livro didático, como uma das manifestações da ideologia da classe dominante, pode ser considerado mentiroso, arcaico, falso etc.". No entanto, a autora acredita que o livro didático reproduz a ideologia da classe dominante, mostrando a visão idealista da burguesia. Nesse caso, afirma que "a aparente falsidade é justamente a visão idealista burguesa que não apreende a base material e transmite seus interesses de classe como interesses universais" (1996, p. 70). 
Ainda nesta mesma perspectiva, Faria (1996, p. 70-71) afirma que:

A contradição realidade-discurso encontrada no livro didático é própria da ideologia burguesa, é uma influência antidialética sobre o pensamento, o discurso não é ilusório, o que é ilusório é considerar a produção intelectual desligada da base material, com vida própria.

Tal corrente de pensamento trazia, muitas vezes de maneira explícita, a ideologia como uma elaboração realizada conscientemente pela classe detentora do poder no intuito de dissimular as contradições sociais existentes, apresentando um mundo homogêneo e sem conflitos. ${ }^{5}$

Ademais, concordamos que "estas posturas dicotômicas do social trazem em seu bojo, por detrás de um discurso aparentemente 'revolucionário', um mal disfarçado autoritarismo, que arroga para si a 'racionalidade do real', a verdade absoluta e inquestionável' (GALZERANI, 1997, p. 109. Grifos da autora). E ainda, além de tudo, tais concepções não consideram professores e alunos, usuários privilegiados dos textos escolares, como seres que questionam e transgridem aquilo que se apresenta inscrito como verdade inquestionável, apresentando-os como 'tábulas rasas'.

$\mathrm{Na}$ verdade, a 'outra História' (a não oficial), defendida por alguns desses autores, ${ }^{6}$ não seria menos ideológica, pois se pensarmos nessa lógica dualista, a outra História, aquela da classe

Interessante estudo acerca da ideologia pode ser encontrado em Chauí (1980; 2006).

6 Ver, por exemplo: Munhoz, 1986.

7 Interessante artigo intitulado Ensino, Ideologia, conhecimento, escrito por Marcos Silva (1986), utilizando-se de uma excelente metáfora, o cemitério dos vivos, critica a perspectiva ideológico-reprodutivista da escola de uma maneira geral e do ensino de História em particular. Silva (1986) afirma que "o conceito da ideologia se mantém freqüentemente no vocabulário das Ciências Humanas sob o signo da negatividade” (p. 15). Outro artigo, bem mais recente, escrito pela professora Rosa Godoy Silveira (2006), tece suas ideias na mesma metáfora dos cemitérios e chega à conclusão de que a paz dos cemitérios educativos/escolares (ou seja, a História vista como um dado acabado e inquestionável) faz gerar conflitos, pois não valoriza a pluralidade de pensamentos e esvazia toda e qualquer possibilidade de debate e discussão, silenciando, assim, as vozes dissonantes da História. Deste modo, defende um ensino de História não com tal ou qual ideologia ou versão, mas como conflito de ideias, que possibilite ao aluno ter uma dimensão/leitura crítica do mundo. 
dominada, representaria a ideologia dessa classe, só se inverteria "o lado da moeda".?

Nessa rápida apreciação dessas produções, denominadas por Munakata de 'as belas mentiras', percebemos uma visão/ avaliação quase que esquizofrênica do livro didático, donde de fato se "flagrava ideologia em cada frase, palavra ou vírgula" (MUNAKATA, 2004, p. 10). Contudo, precisamos ponderá-las remetendo-as ao período em que foram produzidas, sob o risco de incorrermos no mais temível erro do historiador: o anacronismo. Nesse sentido,

Livro didático (e paradidático) era compreensivelmente objeto de suspeição, do mesmo modo que era suspeita - e não sem razão - toda a organização escolar consolidada pela ditadura. [...] Por isso, não surpreende que os livros didáticos de História e Estudos Sociais tivessem sido alvo preferencial do gênero As Belas Mentiras (MUNAKATA, 2003, p. 271. Grifo do autor).

A década de 1990, contudo, trouxe novas problemáticas aos pesquisadores do livro didático. As análises que focalizavam a escola e os manuais escolares como sendo 'aparelhos de reprodução da ideologia dominante', assim como apregoou um dos grandes influenciadores dessa corrente de pensamento, Althusser (1974), foram logo entrando em descrédito. Nesse momento da historiografia ocidental, percebemos a grande influência das ideias de Chartier (1990; 1999a; 1999b; 2001). As 'práticas' e as 'representações' começaram a fazer parte das reflexões dos pesquisadores brasileiros, sobretudo no que diz respeito às 'práticas de leitura e escrita', consideradas pelo autor como criadoras e inventivas.

Bittencourt, sensível a essas mudanças historiográficas, traz, em sua tese de doutorado, Livro didático e conbecimento histórico: uma História do saber escolar, reflexões sobre as formas de utilização dos livros didáticos, compreendendo que cada leitor se apropria do texto lido a sua maneira, de acordo com suas expectativas, experiências e repertório teórico. Apesar disso, não abandona a questão da ideologia nos manuais escolares, pelo contrário, reforça 
essa categoria de análise, sem, contudo incorrer à "caça às bruxas do período anterior".

A tese da professora Bittencourt foi transformada em livro pela Editora Autêntica em 2008 e se intitula Livro Didático e Saber Escolar (1810-1910). A obra é prefaciada por Alain Chopin, um dos mais importantes pesquisadores franceses sobre o livro didático. Chopin (2008), acerca do trabalho desenvolvido por Bittencourt, chega a afirmar, no referido prefácio, que este é "um dos raros trabalhos de síntese jamais realizados no mundo sobre a História do livro escolar e, com certeza, um dos mais completos e bem sucedidos" (p. 10). E termina seu texto afirmando: "o livro que o leitor tem em mãos é, simplesmente, o ato fundador da pesquisa sobre o manual escolar no Brasil" (p. 12).

De fato, a tese da referida autora, defendida no ano de 1993, marcaria, indelevelmente, a historiografia sobre os manuais escolares brasileiros. Seria um 'divisor de águas' em relação às pesquisas anteriores: aquelas realizadas, mormente, em fins de 1970 e em toda a extensão da década de 1980, que valorizavam, sobretudo, questões ideológicas, erros conceituais e preconceitos de toda ordem veiculados nos textos escolares.

A professora Bittencourt apresenta, como proposta de seu texto, analisar os manuais didáticos de forma ampla. Não somente pela vastidão de seu recorte temporal, que corresponde aos anos de 1810 a 1910, mas também devido às suas análises abarcarem desde a vinculação dos livros escolares no que se refere ao poder instituído, onde a ingerência do Estado - seja ele imperial ou republicano - se fez sentir, até na própria forma de utilização deste livro por alunos e professores. Nesse sentido, percebemos uma renovação em suas reflexões, tendo em vista o seu Pátria, civilização e trabalho (1990), ${ }^{8}$ que via no Estado o grande representante da classe dominante, levando-nos a crer a escola como aparelho de reprodução da ideologia burguesa.

8 Essa publicação é oriunda de sua Dissertação de Mestrado, defendida em 1988, junto ao Programa de Pós-Graduação em História Social da Universidade de São Paulo. 
Entrevista a editores e autores, assim como a usuários de livros didáticos, sejam eles professores, alunos ou antigos alunos, para apreender suas concepçóes e leituras sobre os textos escolares, são cada vez mais utilizadas nas pesquisas sobre manuais didáticos. Assim, delineia-se um fecundo espaço de diálogos, em que se vislumbram não só aquilo que está inscrito no livro, mas também as leituras que seus usuários os dão, ou seja, as formas de recepção.

No começo da década de 1980, podíamos "contar nos dedos os textos sobre livro didático no Brasil” (OLIVEIRA et al, 1984, p. 19). Contudo, atualmente, com a expansão dos programas de pósgraduação em Educação e em História, já dispomos de uma gama de importantes trabalhos acerca dos livros didáticos em geral e de História, em particular, que vão desde sua editoração até sua utilização em sala de aula, abordando questôes ideológicas, mercantis, pedagógicas, político-curriculares e etc. Enfim, o panorama das pesquisas dos livros didáticos no Brasil é altamente frutífero. ${ }^{9}$

Assim como afirma Oliveira (2008, p. 29):

Hoje, diferentes abordagens cortam, atravessam, tangenciam, decompõem a história ensinada sob diversos pontos de vista e referenciais teóricos e põe à nossa disposição um conjunto de conclusões bastante híbridas - embora, plenamente justificáveis, posto que a escrita da história muda por conta das próprias mudanças dos historiadores, do tempo, dos métodos e dos instrumentos da própria ciência da História.

Além do mais, lembraríamos que Carr (1982), no começo da década de 1960, em suas conferências na Universidade de Cambridge, já preconizava, em excelente metáfora, o historiador como um "figurante caminhando com dificuldade no meio da procissão" e não como uma "águia observando a cena de um penhasco solitário ou como um VIP no palanque" (CARR, 1982, p. 71). Nesse sentido, o historiador, além de um "ser humano individual, é um fenômeno social, tanto o produto, como o porta-voz consciente ou incons-

9 Uma interessante pesquisa acerca das memórias de antigos usuários de livros didáticos, destacando-se as características materiais e simbólicas desses livros, pode ser encontrada em Fernandes, 2004. Em Helenice Rocha (2009) encontramos um estudo das formas de recepção dos usuários de livros escolares. Ver também: Munakata (2007). 
ciente da sociedade a qual pertence" (ibidem, p. 71). Suas obras, portanto, muitas vezes, dizem mais sobre a sociedade da época em que foram produzidas do que propriamente do período em que o historiador se propôs em analisar.

Destarte, as produções dos historiadores são duplamente históricas; uma porque o pesquisador, ao delimitar um período de análise, trata de uma sociedade específica num período histórico determinado. Outra porque a sua própria produção é histórica, ou seja, temporal, pois se liga diretamente à época de sua produção. Assim, novamente voltando à metáfora da procissão:

À medida que a procissão serpenteia, desviando-se ora para a direita e ora para a esquerda, algumas vezes dobrando-se sobre si mesma, as posições relativas das diferentes partes da procissão estão constantemente mudando, de maneira que pode perfeitamente fazer sentido coerente dizer, por exemplo, que nós estamos mais próximos hoje da Idade Média do que nossos bisavós estavam há cem anos atrás [...] (CARR, 1982, p. 71).

Então, nós interrogamos o passado - ou os vestígios que dele podemos apreender - através de inquietudes que se vinculam ao momento histórico em que vivemos. Talvez a partir daí entendamos os diferentes posicionamentos que se sucederam relativos ao livro didático.

\section{Referências}

ALTHUSSER, Louis. Ideologia e aparelhos ideológicos de Estado. Lisboa: Presença: Martins Fontes, 1974.

BITTENCOURT, Circe. Ensino de história: fundamentos e métodos. São Paulo: Cortez, 2004.

. Livros didáticos entre textos e imagens. In: BITTEN-

COURT, Circe (Org.). O saber histórico na sala de aula. São Paulo: Contexto, p. 69-90, 2008. 
. Livro didático e saber escolar 1810-1910. Belo Horizonte:

Autêntica Editora, 2008.

. Pátria, Civilização e Trabalho: O Ensino de Historia nas Escolas Paulistas - 1917-1939. São Paulo: LOYOLA, 1990.

CAIMI, Flávia Eloísa. O livro didático: algumas questões. In: DIEHL, Astor Antônio (Org.). O livro didático e o currículo de história em transição. Passo Fundo: Ediupf, 1999.

CARR, Edward Hallet. Que é História? Rio de Janeiro: Paz e Terra, 1982.

CASSIANO, Célia Cristina de Figueiredo. Circulação do livro didático: entre práticas e prescrições. 2003. Dissertação (Mestrado em Educação) - Pontifícia Universidade Católica de São Paulo, São Paulo, 2003.

. Mercado de livro didático no Brasil: Anais do I Seminário Brasileiro sobre Livro e História Editorial. Casa de Rui Barbosa, Rio de Janeiro, 2004.

- Aspectos politicos e econômicos da circulação do livro didático de História e suas implicações curriculares: História. São Paulo: p. 23, 2004.

. O mercado do livro didático no Brasil: da criação do Programa Nacional do Livro Didático (PNLD) à entrada do capital internacional espanhol 1985-2007. Tese (Doutorado em Educação) Pontifícia Universidade Católica de São Paulo, São Paulo, 2007.

CERTEAU, Michel de. A escrita da história. Rio de Janeiro: ForenseUniversitária, 1982.

CHARTIER, Roger. A história cultural: entre práticas e representações. Rio de Janeiro: Bertrand Brasil, 1990.

$\overline{\text { Editora UNESP, }} 1999$.

. A aventura do livro: do leitor ao navegador. São Paulo:

. A ordem dos livros: leitores, autores e bibliotecas na Europa entre os séculos XIV e XVIII. Brasília: Editora Universidade de Brasília, 1999. 
dade, 2001.

. (Org.). Práticas da Leitura, São Paulo: Estação Liber-

CHAUI, Marilena de Souza. Cultura e democracia: o discurso competente e outras falas. 11. ed. São Paulo: Editora Cortez, 2006.

. O que é ideologia? São Paulo: Brasiliense, 1980.

CHOPIN, Alain. Prefácio. In: BITTENCOURT, Circe. Livro didático e saber escolar 1810-1910. Belo Horizonte: Autêntica Editora, 2008.

. História dos livros e das edições didáticas: sobre o estado da arte. Educação e Pesquisa, São Paulo, v. 30, n. 3, p. 549-566, set./dez. 2004.

CORRÊA, Rosa Lydia Teixeira. O livro escolar como fonte de pesquisa em História da Educação. Caderno CEDES, São Paulo, n. 52, p. 11 24,2000 .

COSTA, Aryana Lima; OLIVEIRA, Margarida Maria Dias de Oliveira. O ensino de História como objeto de pesquisa no Brasil: no aniversário de 50 anos de uma área de pesquisa, notícias do que virá. Saeculum - Revista de História (UFPB), João Pessoa, ano 13, n. 16, p. 147-160, jan./jun. 2007.

FARIA, Ana Lúcia. A ideologia no livro didático. São Paulo: Cortez Editora, 1996.

FERNANDES, Antonia Terra de Calazans. Livro didático em dimensões materiais e simbólicas. Educação e Pesquisa (USP), São Paulo, v. 30, n. 3, p. 531-545, 2004.

FONSECA, Selva Guimarães. Didática e prática do ensino de História: experiências, reflexões e aprendizados. Campinas, São Paulo: Papirus, 2003.

GALZERANI, Maria Carolina Bovério. Belas mentiras? A ideologia nos estudos sobre o livro didático. In: PINSKY, Jaime (Org.). O ensino de História e a criação do fato. São Paulo: Contexto, p. 105-109, 1997.

GATTI Jr., Décio. A escrita escolar da História: livro didático e ensino no Brasil (1970-1990). Bauru: EDUSC; Uberlândia: EDUFU, 2004.

. Estado e editoras privadas no Brasil: o papel e o

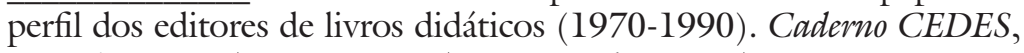
Campinas, v. 25, n. 67, p. 365-377, set./dez. 2005. 
MESQUITA, Ilka Miglio de; ZAMBONI, Ernesta. A formação de professores na trajetória histórica da Associação Nacional de História (ANPUH). In: FONSECA, Selva Guimarães; ZAMBONI, Ernesta (org.). Espaços de formação do professor de História. Campinas, São Paulo: Papirus, p. 131-162, 2008.

MUNAKATA, Kazumi. Produzindo livros didáticos e paradidáticos. 1997. 206fs. Tese (Doutorado em Educação) - Pontifícia Universidade Católica de São Paulo, São Paulo, 1997.

. Histórias que os livros didáticos contam, depois que acabou a ditadura no Brasil. In: FREITAS, Marcos Cezar (Org.). Historiografia brasileira em perspectiva. 5 ed. São Paulo: Contexto, p. 271-296, 2003.

. Um prefácio desnecessário. In: GASPARELLO, Arlette Medeiros. Construtores de identidades: a pedagogia da nação nos livros didáticos da escola secundária brasileira. São Paulo: Iglu. 2004.

. O livro didático e o professor: entre a ortodoxia e a apropriação. In: MONTEIRO, Ana Maria; GASPARELLO, Arlette Medeiros; MAGALHÃES, Marcelo de Souza. Ensino de História: sujeitos, saberes e práticas. Rio de Janeiro: Mauad X: FAPERJ, p. 137-147, 2007.

MUNHOZ, Sidnei José. Para que serve a História ensinada nas escolas. In: SILVA, Marcos Antônio da (Org.). Repensando a História. 2 ed. São Paulo: Anpuh: Marco Zero, p. 65-68, 1986.

NOSELLA, Maria de Lurdes Chagas Deiró. As belas mentiras: a ideologia subjacente aos textos didáticos. São Paulo: Moraes, 1981.

OLIVEIRA, Itamar Freitas de. Livro didático de História: definições, representações e prescrições de uso. In: OLIVEIRA, Margarida Maria Dias de; OLIVEIRA, Almir Félix Batista de. Livros didáticos de História: escolhas e utilizações. Natal: EDUFRN, p. 11-19, 2009.

. A pedagogia histórica de Jonathas Serrano: uma teoria do ensino de história para a escola secundária brasileira (1913-1935). São Cristovão: Editora UFS; Aracaju: Fundação Oviêdo Teixeira, 2008.

. O direito ao passado: uma discussão necessária à formação profissional de História, 2003. 291fs. Tese (Doutorado em História) - Universidade Federal de Pernambuco, Recife, 2003. 
OLIVEIRA, João Batista Araújo e; GUIMARÃES, Sônia Dantas Pinto; BOMÉNY, Helena Maria Bousquet. A politica do livro didático. São Paulo: Summus, 1984.

ROCHA, Helenice Aparecida Bastos. Livros didáticos de História: a diversidade de leitores e de usos. In: ROCHA, Helenice; REZNIK, Luís; MAGALHÃES, Marcelo (Org.). A História na Escola: autores, livros e leituras. Rio de Janeiro: Editora FGV, p. 201-226, 2009.

RÜSEN, Jörn. Didática da História: passado, presente e perspectivas a partir do caso alemão. Revista Práxis Educativa, Ponta Grossa, v. 1, n. 2, p. 07-16, jul./dez. 2006.

SILVA, Marcos. Desavir-se, reaver-se. História e ensino de história: interfaces ou intrafaces? Textos de história, Brasília, v. 15, n. 1/2, p. 275-288, 2007.

A vida e o cemitério dos vivos. In: SILVA, Marcos A. da (Org.). Repensando a História. 2 ed. São Paulo: Anpuh/Marco Zero, p. 15- 24, 1986.

SILVEIRA, Rosa Maria Godoy. De como o ensino de história constrói a paz ... dos cemitérios e, assim, serve à guerra. Saeculum, Revista de História (UFPB), João Pessoa, v. 15, p. 11-17, 2006. 
